\title{
Evaluation of the Relationship Between Family History of Breast Cancer and Risk Perception and Impacts on Repetition of Mammography
}

\author{
Sahar Khoshravesh ${ }^{1}$, Parvaneh Taymoori ${ }^{2 *}$, Daem Roshani ${ }^{2}$
}

\begin{abstract}
Since the mean age of breast cancer in women living in developing countries, compared with those in developed countries, is lower by about 10 years, repetition of mammography can play an important role in reducing morbidity and mortality. Hence, this study aimed to investigate the relationship between family history of breast cancer and risk perception and its impact on repetition of mammography. In this cross-sectional study, 1,507 women aged 50 years and older, referred to the mammography center of Regions 1 and 6 in Tehran, Iran, were enrolled. Data were collected using a self-report questionnaire and analyzed using SPSS and LISREL. According to our findings, knowledge about the time interval of mammography was found to have the highest correlation with repetition of mammography $(r=0.4)$. Among the demographic variables, marital status $(\beta=-0.1)$ and family history of breast cancer $(\beta=0.1)$ had the most direct and significant impact on repetition of mammography $(\mathrm{P}<0.05)$. Among the other variables studied, knowledge $(\beta=-0.5)$ had the highest direct and significant impact on repetition of mammography $(\mathrm{P}<0.05)$. Family history of breast cancer was one of the predictors of repetition of mammography, but the results did not prove any relationship with risk perception. Further studies are needed to assess the effect of risk perception and knowledge about time interval on the initiation and continuation of mammography.
\end{abstract}

Keywords: Breast cancer - family history - risk perception - repetition of mammography

Asian Pac J Cancer Prev, 17, , Cancer Control in Western Asia Special Issue, 135-141

\section{Introduction}

Iranian women are at a high risk for non-adherence to recommended guidelines and subsequent late stage breast cancer diagnoses, due to lack of awareness about breast cancer (Montazeri et al., 2008; Thomas et al., 2011), cultural beliefs such as cancer fatalism and prioritization of family over personal health (Lamyian et al., 2007; Taymoori et al., 2012), previous adverse experiences (e.g., painful mammography) (Taymoori et al., 2013) embarrassment, and lack of access to healthcare (Keshavarz et al., 2011).

Planning and evaluating interventions that promote regular, continued mammography requires careful consideration (Vernon et al., 2010). In the last decade, the importance placed on theory when planning interventions has increased (Moodi et al., 2011; Farhadifar et al., 2016 ). Perceived breast cancer risk depends on psychological and cognitive variables, and influences adherence to mammography screening guidelines. Perceived risk is an important motivator for protective health-related behaviors. Risk perception is a subjective judgment made by individuals regarding the characteristics and severity of a risk (Glanz et al., 2008) .
Understanding of risk, and cancer preventive behaviors (Zikmund-Fisher et al., 2010), previous studies on the relationship between risk perception and mammography use have shown varied, and often inconclusive results. The recent studies applicable to the present research show mixed results. Kim et al., (2008) examined the association between cancer risk perception and screening behavior for cervical, breast, and colon cancers in women. Researchers (Bowen et al., 2004) showed similar results with no statistically significant relationship between risk perception and mammography. Two studies (Facione, 2002; Calvocoressi et al., 2004) showed that women who believed their susceptibility was high were less likely to be screened. Finally, (Katapodi et al., 2004), a meta-analytic review found that women who perceived a higher breast cancer risk were more likely to have mammograms although the association was weak (Katapodi et al., 2004). The association between risk perception and repetition of mammography influenced by demographic characteristics (Katapodi et al., 2004), addressed the influence of demographic characteristics on breast cancer perceived risk, and results were inconclusive. For example, some studies concluded that younger women were more likely to perceive higher 
risk for developing breast cancer than were older women, and other studies found no significant relationship between older age and increased perceived risk (Katapodi et al., 2004). There were not reported differences in the perception of risk by income level. Findings on education and perceived risk showed women with high school or less education were more likely to be either unaware of their risk or overestimate their risk, whereas women with college education were less likely to have an optimistic bias. Some studies reported no association between educational level and perceived risk.

The relationship between risk perception and mammography use may be effected by family history of breast cancer. Family history of breast cancer could influence risk perception and repetition of mammography. Multiple studies indicate that family history of breast cancer is the risk factor upon which women base their own risk perception (Buxton et al., 2003; Silk et al., 2006; Caruso et al., 2009). Research suggests women rely on family history of breast cancer to determine their breast cancer risk, despite the fact that approximately $80 \%$ of breast cancers are not familial/genetically related. Multiple studies indicate that family history of breast cancer is the risk factor on which women base their own risk perception. Over-reliance on family history of breast cancer to determine one's own breast cancer risk may skew not only perception of developing breast cancer, but also may impact rates of repetition of mammography. Given the importance that women place on family history of breast cancer, the aim of this research is to understand the strength of the relationship between family history of breast cancer (BC), and family history of cancer other than breast cancer (OC) with perceived risk of developing cancer and with repetition of mammography.

Another possible contribution to inconclusive results is that the association between risk perception and repetition mammography could lie in the type of scale used to measure perceived risk: numerical or verbal.

The objective of the current study was to determine the strength of the relationship between family history of breast cancer and other cancer to perceived risk of developing cancer and repetition of mammography. In addition, we examined both direct and indirect effects of included variables on number of mammography.

\section{Materials and Methods}

This study was a cross-sectional study. A total of 1620 women, aged 50 years and older who referred to mammography centers in two regions of Tehran (Regions 1 and 6) were selected via convenience sampling method and were invited to participate in the study. Of all, a total of 1593 women consented to participate in the study. Of all the participants, 60 women were excluded as they did not meet the inclusion criteria; in addition, 26 women were excluded as they presented incomplete data. The final sample size included 1507 persons. The participants' response rate was $93 \%$. The inclusion criteria were as follows: being aged 50 years and older, having a history of repeated mammography in the past five years, and the ability to read and write. Exclusion criteria were the
Table 1. Demographic Characteristics

\begin{tabular}{lcccc}
\hline Variables & $\mathrm{N}$ & $\%$ & Mean & $\mathrm{SD}$ \\
\hline Age & & & 58.9 & 6.4 \\
Marital status & & & & \\
$\quad$ Single & 414.0 & 27.5 & & \\
$\quad$ Married & $1,093.0$ & 72.5 & & \\
Educational Status & & & & \\
$\quad$ Academic & 287.0 & 19.0 & & \\
$\quad$ Non Academic & $1,220.0$ & 81.0 & & \\
Employment Status & & & & \\
$\quad$ employed & 771.0 & 51.2 & & \\
$\quad$ employed & 736.0 & 48.8 & & \\
Insurance Status & & & \\
$\quad$ Yes & $1,330.0$ & 88.3 & \\
$\quad$ No & 177.0 & 11.7 &
\end{tabular}

Breast cancer family history

$\begin{array}{ccc}\text { Yes } & 233.0 & 15.5 \\ \text { No } & 1,274.0 & 84.5\end{array}$

Other cancer family history

$\begin{array}{ccc}\text { Yes } & 65.0 & 4.3 \\ \text { No } & 1,442.0 & 95.7\end{array}$

Breast Self-Examination

$\begin{array}{lcc}\text { Regular } & 121.0 & 8.0 \\ \text { Irregular } & 212.0 & 14.1 \\ \text { Not doing } & 1,174.0 & 77.9 \\ \text { Clinical Breast Examination } & \\ \text { Yes } & 336.0 & 22.3 \\ \text { No } & 1,171.0 & 77.7\end{array}$

Knowledge of the interval mammography

$\begin{array}{lcc}\text { annual } & 498.0 & 33 \\ \text { 2-3 years } & 306.0 & 20.3 \\ 3 \text { years }> & 703.0 & 46.6\end{array}$

Perceived threat

Mean of repetition mammogram

\begin{tabular}{ccc}
1 & 633.0 & 42.0 \\
2 & 269.0 & 17.9 \\
3 & 465.0 & 30.9 \\
4 & 114.0 & 7.6 \\
$\geq 5$ & 26.0 & 1.7 \\
\hline
\end{tabular}

followings: being affected by breast cancer, pregnancy, and breast feeding.

The questionnaire included the demographic data (age, marital status, education level, insurance coverage, family history of breast cancer and other types of cancer). In addition, the status of breast self-exam was determined and classified into three categories of regular self-exam, irregular self-exam, and lack of self-exam. The time interval of mammography in women was determined though choosing one of the three following options: once a year, once every two to three years, and once more than every three years. The status of clinical breast exam was determined through choosing one of the three following options: annual regular CBE, irregular CBE 
Table 2. Direct and Indirect Effects between Demographic Variables and Repetition Mammogram

\begin{tabular}{|c|c|c|c|c|}
\hline \multirow{2}{*}{$\begin{array}{l}\text { Predictor } \\
\text { variables }\end{array}$} & \multirow{2}{*}{ Through } & \multicolumn{3}{|c|}{ Causal effect } \\
\hline & & Direct & Indirect & Total \\
\hline \multirow[t]{2}{*}{ Age } & & 0.0 & - & \\
\hline & $\begin{array}{c}\text { Perceived threat } \\
\text { Mean }\end{array}$ & - & 0.0 & \\
\hline
\end{tabular}

Marital

Insurance

$\begin{array}{lcc} & 0.0 & - \\ \text { Perceived threat } & - & 0.0 \\ \text { Mean } & & \end{array}$

Family

history of

breast cancer

Perceived threat $\quad-\quad-0.1^{*}$
Mean

Family

history of

other cancer

$$
\begin{gathered}
\text { Perceived threat } \\
\text { Mean }
\end{gathered}
$$

$\begin{array}{lcc} & -0.1^{*} & - \\ \text { Perceived threat } & - & -0.1^{*} \\ \text { Mean } & & \end{array}$

proposed model was considered to be a suitable model. In this study, it was assumed that the variables of age, marital status, insurance status, knowledge of the mammograms time intervals, family history of breast cancer, and family history of other cancers had direct or indirect impacts on the women's risk perception and were a predictor of repetition of mammography.

In this study, based on theoretical and empirical backgrounds, it was assumed that the variables of age (Al-Naggar and Bobryshev, 2012; Mokhtari et al., 2011), marital status (Al-Naggar and Bobryshev, 2012; Mokhtari et al., 2011), insurance status (Al-Naggar and Bobryshev, 2012; Mokhtari et al., 2011), knowledge of mammography time intervals (Banaeian et al., 2006; Godazandeh et al., 2006) , family history of breast cancer (Taylor et al., 1995; Murabito et al., 2001; Laing and Makambi, 2008), and family history of other cancers (Haber et al., 2012) were among the most important factors which influenced the mammography screening behavior and repetition of mammography. According to health belief model, the increase in the perceived risk of a disease (breast cancer) can lead to related screening behavior (mammography). In addition, the results of empirical studies have verified the effect of risk perception on the repetition of mammography (Taylor et al., 1995; Murabito et al., 2001; Laing and Makambi, 2008). Therefore, in this study we evaluated the direct and indirect effects of the mentioned variables on the perceived risk of breast cancer and its subsequent impact on repetition of mammography (Figure 1).

once every several years, and lack of CBE. To measure the risk perception, we used a 5-item Likert scale with 10 questions (the scale ranged from strongly disagree $=$ 1 to strongly agree $=5$ ). The Champion's Health Belief Model inventory was used as the source of questions about risk perception(Champion, 1993; Champion, 1999). In order to assess the validity of risk perception questions, the questions were reviewed and revised by two health education and health promotion experts working in Kurdistan University of Medical Sciences. The reliability of the questionnaire was assessed through test-retest within two weeks in 50 randomly selected people $(\mathrm{r}=$ 0.82). In this study, repetition of mammography means a history of at least two mammograms during the last five years.

\section{Data Analysis}

After collecting data, frequencies, means, and Pearson correlation were calculated using SPSS version 22. To determine the direct, indirect, and general effects of the studied variables on the outcome variable (repetition of mammography), we used path analysis technique which is available in LISREL software. Fitness of the model was assessed using X2, RMSEA (Root Mean Squares of Error Approximation), AGFI (Adjusted Nor med Fit Index) , NFI (Nor med Fit Index), and GFI (Goodness of Fit Index) tests. As the Adjusted Goodness-of-Fit Index (AGFI) was greater than 0.8, RMSEA was less than 0.08 , and GFI, and NFI indices were higher than 0.9, the

\section{Results}

The mean age of the studied participants was $63.6 \pm$ 37.6 years. The highest rate of repetition of mammography was $42 \%$, with a mean frequency of one repetition, and the lowest rate of repetition was $1.7 \%$ with a mean frequency of five times or more.

Table 1 presents the demographic and social characteristics of the subjects. Except for the variable of family history of other cancers, all the variables (including the knowledge of the time interval between mammography, risk perception, family history of breast cancer, breast self examination, and clinical breast examinations) were significantly associated with the repetition of mammography $(P<0.05)$. The knowledge of the time interval between mammography had the highest correlation with the repetition of mammography $(r=0.4)$. In addition, the clinical breast exam and family history of breast cancer were the next variables which had the highest correlation with repetition of mammography ( $r=$ 0.2 and $r=0.21$, respectively).

Table 2 presents the variables correlation matrix. After evaluating the regression coefficients of all the variables, they were analyzed using path analysis technique. Among the demographic variables, marital status with a regression coefficient of $\beta=-0.06$ had a direct significant negative effect on repetition mammography. In addition, marital status influenced risk perception and had an indirect significant negative effect on repetition mammography. $(\beta=-0.1)$. Family history of breast cancer with a 
Table 3. Direct and Indirect Effects between Other Variables and Repetition Mammogram

\begin{tabular}{|c|c|c|c|c|}
\hline \multirow{2}{*}{ Predictor variables } & \multirow[t]{2}{*}{ Through } & \multicolumn{3}{|c|}{ Causal effect } \\
\hline & & Direct & Indirect & Total \\
\hline Knowledge of the interval mammography & & $0.1^{*}$ & - & \\
\hline & $\begin{array}{c}\text { Perceived threat } \\
\text { Mean }\end{array}$ & - & 0.0 & \\
\hline
\end{tabular}

Perceived threat

Mean
0.0

\author{
Breast Self-Examination \\ Clinical Breast Examination
}

$\begin{array}{ll}- & -0.0 \\ - & -0.0\end{array}$

$-0.0$
Breast Self-Examination

Clinical Breast Examination
0.0

0.0
-

$-0.0$

0

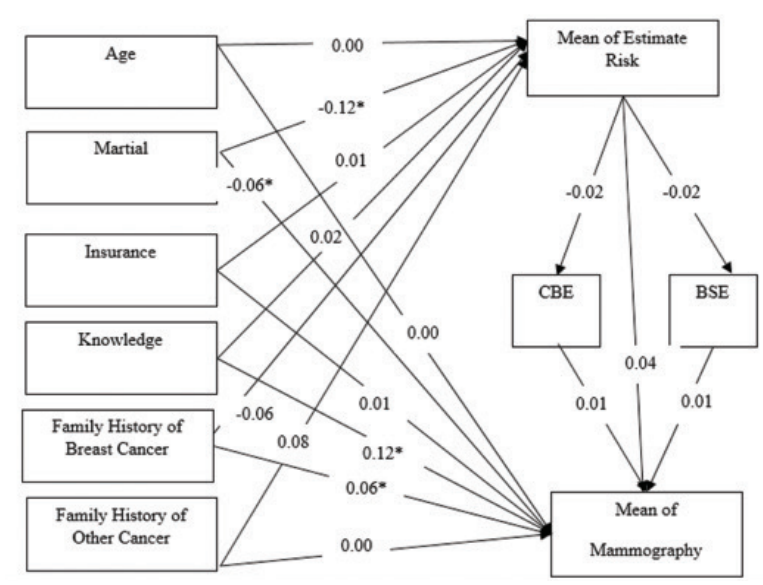

Figure 1. Paths Model with Standardized Coefficients *. Correlation is Significant at the 0.05 Level (2-tailed) / $\mathrm{R}^{2}=0.32$

Note: BSE Breast Self Examination, CBE Clinical Breast Examination

regression coefficient of $\beta=0.1$ had a direct significant positive effect on repetition mammography $(P<0.05)$. Family history of breast cancer influenced by risk perception was not able to indirectly predict repetition of mammography. The analysis of the effects of other variables on repetition of mammography showed that only the variable of the knowledge of the time intervals between mammography, with a regression coefficient of $\beta$ $=0.1$ had a direct positive impact on the repetition of the mammography $(P<0.05)$. Tables 3 and 4 , respectively, show the direct and indirect effects of the demographic variables and other variables on the outcome variable.

The results of fitting the model indicated that the selected indices were relatively suitable. Goodness of Fit Index was as follows: $X^{2}=98.3, \mathrm{df}=14, P<0.01$, RMSEA $=0.1, \mathrm{AGFI}=81.0, \mathrm{GFI}=90.0$, and NFI $=91.0$. Figure 1 presents the paths of the model and the standardized coefficients. The variances of risk perception, breast self examination, clinical breast examination, and repetition of mammography, respectively, were $0.009,0.00,0.001$, and 0.3 . Overall, the model explained $32 \%$ of the variance of repeated mammography behavior in the studied women.

\section{Discussion}

The results of this study showed that of all the studied women, $42 \%$ had repeated mammography at least once and $58 \%$ repeated mammography more than twice after the age of 50. The results of previous studies are consistent with the findings of the present study. Strong conducted a study on Chinese women aged over 50 years old who were living in the US. The results showed that more than $45 \%$ of women had repeated mammography at least twice after the age of 50 (Strong and Liang, 2009). According to Taylor's study, $41 \%$ of the studied women, with a mean age of 53 years, had repeated mammography twice or more (Taylor et al., 1995). Other studies have reported different results about the repetition of mammography. The results of a study on Malaysian women younger than 50 years showed that only $2 \%$ of the studied women underwent regular mammograms every two or three years (Al-Naggar and Bobryshev, 2012). However, the results of Laing's study on African - Americans women, with an age range of 40 to 60 years old, showed that only $73 \%$ had taken annual mammography (Laing and Makambi, 2008). A study on Arab women showed that $26.9 \%$ of women aged 40 years and older repeated mammography every one or two years (Donnelly et al., 2014). The mentioned results are not consistent with our results. It seems that the inconsistency between the results is due to the differences in definitions of repeted mammography and the age range of the studied subjects which differs in the mentioned studies (Taylor et al., 1995; Laing and Makambi, 2008; Strong and Liang, 2009; Al-Naggar and Bobryshev, 2012; Donnelly et al., 2014).

Among the demographic variables, marital status had a direct significant negative effect on the repetition of mammography. Previous studies have shown conflicting results about the relationship between marital status and repetition of mammography. For example, the results of studies by Joun and Qi showed that marital status of women had no significant effects on mammography 
(Joun et al., 2002; Qi et al., 2006), while the results of numerous studies indicate that marital status has a positive effect on doing and repetition of mammography (Ahmadian et al., 2012; Taymoori et al., 2012). It seems that married people because of social support which they receive from their spouses, children, and friends (Lagerlund et al., 2014), in comparison with non-married women, are benefiting from more emotional support (Katapodi et al., 2002). The results of some studied suggest that the presence of social support has a positive effect on undergoing mammography (Farmer et al., 2007; Maxwell et al., 2001) and repetition of mammography (Farmer et al., 2007; Allen et al., 1999). In a study conducted on Swedish women, single women or widows who received less social support, compared with married women, were less interested to undergo mammography (Lagerlund et al., 2014). In this study, the marital status variable influenced by risk perception had a significant indirect effect on repetition of mammography. It is likely that married women, who have more social interactions with family members, have more opportunities to obtain and exchange information about the importance of breast cancer screening (Katapodi et al., 2002). Hence, the availability of data support can enhance the perceived risk of breast cancer (Katapodi et al., 2002; Mishra et al., 2007 ). The results of some studies have shown that the increase in the perceived risk of breast cancer can motivate people to undergo mammography and later repetition (Taylor et al., 1995; Haber et al., 2012). According to the results of Consedine's study, higher levels of perceived risk of breast cancer were important factors influencing mammography screening behavior (Consedine et al., 2005). The increased level of perceived risk of breast cancer promotes the mammography screening behavior (Katapodi et al., 2004); however, an attempt should be made to increase women's risk perception with caution (Taymoori et al,.2015). High risk perception may lead to fear control phenomenon and may prevent women to undergo breast cancer screening and mammography (Witte et al., 2001). When designing and implementing interventions aimed at increasing women's risk perception and encouraging them to do and repeat mammography, the benefits of mammography must be highlighted as well. In line with the results of studies on the relationship between family history of breast cancer and repetition of mammography (Cohen, 2006; Tolma et al., 2011; Al-Naggar and Bobryshev, 2012; Haber et al., 2012), the results of our study showed and confirmed a direct significant positive effect between family history of breast cancer and repetition of mammography. Presence or absence of family history of breast cancer plays an important role in women's decision for repetition of mammography (Tilburt et al., 2011). Women with a family history of breast cancer, compared with those without a family history of breast cancer, consider themselves to be at increased risk of breast cancer and hence they are more prone to do and repeat mammography (Katapodi et al., 2004; Haber et al., 2012). The closer family relationship with someone with breast cancer, the higher the risk perception. It also increases the chance for repetition of mammography. The possibility of repeated mammography in women with maternal history of breast cancer is $50 \%$ more than women without a maternal history of breast cancer (Haber et al., 2012). Women without a family history of breast cancer have a low risk perception and they consider themselves to be protected against breast cancer; hence, such a condition is likely to reduce the rate of repetition of mammography in women (Thomas, 2004; Taymoori et al., 2012). To promote mammography screening, health care providers who are involved in intervention programs always point out that more than $85 \%$ of breast cancer cases occur among women without a family history of breast cancer(Haber et al., 2012).

Women's lack of awareness has been reported as one of the factors which prevent women to take the measures such as mammography for early detection of breast cancer (Harris et al., 2003; Khanjani et al., 2012). About two-thirds of the studied women did not have an exact knowledge about the yearly time intervals of mammography. This finding is in line with the findings of studies by Tolma et al (2011) and Rakowski (2006) which reported that knowledge of mammography time intervals had a direct and significant impact on increased rate of repeated mammography. Women's knowledge can increase the perceived sensitivity and thus enhance mammography screening behavior (Mishra et al., 2007 ). About two-thirds of women did not have an exact knowledge about mammogram yearly time intervals. It is therefore essential for health service providers and physicians to highlight the importance of diagnostic value of mammograms and put emphasis on the regular mammography at the appropriate time intervals. Contrary to the findings of other studies (Katapodi et al., 2004; Allen et al., 1999; Haber et al., 2012), risk perception was not directly a predictor of repetition of mammography behavior. Based on the theoretical foundations of the health belief model, the increase in the perceived risk of a disease (breast cancer) can lead people to display a behavior (mammography) (Glanz et al., 2008). and repeat it (Taylor et al., 1995). There are several explanations for this paradox. First, there are some differences in measuring risk perception, for example, in Haber's study (Haber et al., 2012) risk perception is measured only through one question while in our study we measured mean risk perception using 10 questions. Second, there are some differences in the outcome variable; in our study, repetition of mammography was the outcome variable, while in other studies undergoing mammography was the outcome variable (one case of mammography after age 50) (Allen et al., 1999). Third, although risk perception may lead to the emergence of a behavior (mammography), it might not have the same impact on the behavior to change it into a habit. Further studies are needed to assess the impact of risk perception on the initiation and continuation of the behavior.

Perceived risk indirectly influenced by the two variables of breast self examination and clinical breast examination was not a predictor of repeated mammography. Although our sample included women with a history of repetition of mammography, $22.1 \%$ practiced breast self examination and $22.3 \%$ reported clinical breast examination. Results of a study on Thai women showed that the clinical breast 
examination led to increased rate of mammography. It seems that, after the diagnosis of a problem in the clinical breast exam, women are recommend to do mammography (Tolma et al., 2011; Mukem et al., 2014). There are other factors that predict indirect relationship between risk perception and repetition of mammography. The results of a meta-analysis showed that the level of education, culture, race and anxiety affected risk perception and led to repetition of mammography. For instance, in this study, the results of a meta-analysis of seven studies showed that younger women had higher risk perception than older women; in addition, the meta-analysis of five studies showed that white women considered themselves to be at higher risk of breast cancer than other women (Katapodi et al., 2004). It seems necessary to conduct further studies on the role of interactive factors such as culture (Katapodi et al., 2004), race (Katapodi et al., 2004), history of breast problems (Salimi Pormehr et al., 2010; Naghibi et al., 2014), intensity of emotional reactions such as fear, anxiety (Katapodi et al., 2004), and data collection environment (for example, collecting samples in environments such as hospitals, health care centers, workplaces, or home may lead to differences in people's risk perception) (Katapodi et al., 2004), the mentioned factors may affect the perceived risk of breast cancer and put an impact on repetition of mammography.

This study had some limitations. Firstly, it was a cross-sectional study. Moreover, sampling location and data collection via self-reports increased the probability of bias. The findings of the study might be possibly influenced by the socio-economic status of the studied subjects who had referred to mammography centers in Regions 1 and 6 Tehran. It seems that, Region 1 is a place where wealthy people and Region 6 is a place with relatively prosperous people. One of the other limitations of this study was the difference between the scale used in the current study and those used by other studies to measure the risk perception; it made it difficult to assess our results and compare them with the results of other studies. In addition, the lack of a ranking for different levels of risk perception and the subjective measurement of this variable can affect the results. Utilization of tools which both subjectively and objectively measure risk perception (like the Gail model) (McCarthy et al., 2015) can help to clarify the interaction between risk perception and family history of breast cancer and how they affects repetition of mammography. Finally, we did not consider the number of close family members with breast cancer while this factor may affect the perception of the risk of breast cancer.

Marital status, knowledge of the time interval between mammography, and family history of breast cancer were identified as the predictors of repeated mammography. Family history of breast cancer, indirectly influenced by the risk perception, was not a predictor of repeated mammography. Risk perception had not a direct effect on repetition of mammography. In addition, breast self examination and clinical breast examination did not predict the indirect effect of risk perception on repetition of mammography. It seems necessary to conduct further studies and assess the impact of risk perception and family history of breast cancer on the repetition of mammography behavior.

\section{Acknowledgments}

This article is extracted from Master Thesis by Sahar Khoshravesh, titled "Evaluation of the Relationship between Family History of Breast Cancer and Risk Perception and its Impact on Repetition of Mammography".

\section{References}

Ahmadian M, Samah AA, M.R R, et al (2012). Predictors of Mammography Screening among Iranian Women Attending Outpatient Clinics in Tehran, Iran. Asian Pac J Cancer Prev, 13, 969-74.

Al-Naggar RA, Bobryshev YV (2012). Practice and Barriers of Mammography among Malaysian Women in the General Population. Asian Pac J Cancer Prev, 13, 3595-600.

Allen JD, Sorensen G, Stoddard AM, et al ( 1999). The relationship between social network characteristics and breast cancer screening practices among employed women. Ann Behav Med, 21, 193-200.

Banaeian S, Kheiri S, Kazemiyan AA (2006). Knowledge, attitude and practice about breast cancer screening and related factors among women referred to health care centers in Boroujen in 2005. J Shahrekord Univ Med Sci, 7, 28-34.

Bowen DJ, Alfano CM, McGregor BA, et al (2004). The relationship between perceived risk, affect, and health behaviors. Cancer Detect Prev Suppl, 28, 409-17.

Buxton JA, Bottorff JL, Balneaves LG, et al (2003). Women's perceptions of breast cancer risk: are they accurate. Can $J$ Public Health, 94, 422-6.

Calvocoressi L, Kasl SV, Lee CH, et al (2004). A prospective study of perceived susceptibility to breast cancer and nonadherence to mammography screening guidelines in African American and White women ages 40 to 79 years. Cancer Epidemiol Biomarkers Prevent, 13, 2096-105.

Caruso A, Vigna C, Marozzo B, et al (2009). Subjective versus objective risk in genetic counseling for hereditary breast and/or ovarian cancers. J Exp Clin Cancer Res, 28, 157.

Champion VL (1993). Instrument refinement for breast cancer screening behaviors. Nurs Res, 42, 139-43.

Champion VL (1999). Revised susceptibility, benefits, and barriers scale for mammography screening. 22, 341-8.

Cohen M (2006). Breast cancer early detection, health beliefs, and cancer worries in randomly selected women with and without a family history of breast cancer. Psychooncology, 15, 873-83.

Consedine NS, Magai C, Horton D, et al (2005). Health belief model factors in mammography screening: testing for intractions among subpopulations of Caribbean women. Summer, 15, 444-52.

Donnelly TT, Al Khater A-H, Al-Bader SB, et al (2014). Faactors that influence awareness of breast cancer screening among arab women in qatar: results from a cross sectional survey. Asian Pac J Cancer Prev, 15, 10157-64.

Facione NC (2002). Perceived risk of breast cancer. Cancer Pract, 10, 256-61.

Farhadifar F, Molina Y, Taymoori P, et al (2016). Mediators of repeat mammography in two tailored interventions for Iranian women. BMC Public Health, 16, 149-57.

Farmer D, Reddick B, D'Agostino R, et al (2007). Psychosocial correlates of mammography screening in older African American women. Oncol Nurs Forum, 34, 117-23.

Glanz K, Rimer BK, Viswanath K (2008). Health behavior and health education. Theory, research, and practice, 3, 361-388.

Godazandeh GA, Khani H, Khalilian AR, et al (2006). 
Knowledge and practice of above 15 years old females towards breast cancer prevention in Sari township, 2004. $J$ Mazandaran Univ Med Sci, 16, 64-76.

Haber G, Ahmed NU, Pekovic V ( 2012). Family History of Cancer and Its Association With Breast Cancer Risk Perception and Repetition Mammography. Am J Public Health, 102, 2322-9.

Harris DM, Miller JE, Davis DM (2003). Racial differences in breast cancer screening, knowledge and compliance. J Natl Med Assoc, 95, 693-701.

Joun HS, Seo YJ, Kim MT (2002). Breast and cervical cancer screening among Korean American elderly women. European journal of oncology nursing. Eur J Oncol Nurs, 6, 228-35

Katapodi MC, Facione NC, Miaskowski C, et al (2002). The influence of social support on breast cancer screening in a multicultural community sample. Oncol Nurs Forum, 29, 845-52.

Katapodi MC, Lee KM, Facione NC, et al (2004). Predictors of perceived breast cancer risk and the relation between perceived risk and breast cancer screening: a meta-analytic review. Prev Med, 38, 388- 402.

Keshavarz Z, Simbar M, Ramezankhani A (2011). Factors for performing breast and cervix cancer screening by Iranian female workers: a qualitative-model study. Asian Pac $J$ Cancer Prev, 12, 1517-22.

Khanjani N, Noori A, Rostami F (2012). The knowledge and practice of breast cancer screening among women in Kerman, Iran. Al-Ameen J Med Sci, 5, 221-6.

Kim SE, Pérez-Stable EJ, Wong S, et al (2008). Association between cancer risk perception and screening behavior among diverse women. Arch Intern Med, 168, 728-34.

Lagerlund M, Sontrop JM, Zackrisson S (2014). Psychosocial factors and attendance at a population-based mammography screening program in a cohort of Swedish women. $B M C$ Womens Health, 14, 33-8.

Laing SS, Makambi K (2008). Predicting Regular Breast Cancer Screening inAfrican-American Women with a Family History of Breast Cancer. J Natl Med Assoc, 100, 1309-17.

Lamyian M, Hydarnia A, Ahmadi F, et al (2007). Barriers to and factors facilitating breast cancer screening among Iranian women: a qualitative study. East Mediterr Health J, 13, $1160-9$.

Maxwell CJ, Bancei CM, Snider J ( 2001). Predictors of mammography use among Canadian women aged 50-69: findings from the1996/97 National Population CMAJ, 164, 329-34.

McCarthy AM, Keller B, Kontos D, et al (2015). The use of the Gail model, body mass index and SNPs to predict breast cancer among women with abnormal (BI-RADS 4) mammograms. Breast Cancer Res, 17, 1-6.

Mishra St, Bastani R, Crespi CM, et al (2007 ). Results of arandomized trial to increase mammogram usage among Samoan women. Cancer Epidemiol Biomarkers Prev, 16, 2594-604.

Mokhtari L, Baradaran Rezaee M, Mohammadpour Asl A, et al (2011). Health beliefs about mammography and clinical breast examination among female healthcare providers in Tabriz health centers. Iran J Nurs, 24, 63-73.

Montazeri A, Vahdaninia M, Harirchi I, et al (2008). Breast cancer in Iran: need for greater women awareness of warning signs and effective screening methods. Asia Pac Fam Med, 7, 6-9.

Moodi M, Mood M, Sharifirad G, et al (2011). Evaluation of breast self-examination program using Health Belief Model in female students. $J$ Res Med Sci, 16, 316-22.

Mukem S, Sriplung H, McNeil E, et al (2014). Breast
DOI:http://dx.doi.org/10.7314/APJCP.2016.17.S3.135

Impact Risk Perception on Repetition of Mammography

cancer screening among women in Thailand: analyses of population-based household surveys. J Med Assoc Thai, 97, 1106-18.

Murabito JM, Evans JC, Larson MG, et al (2001). Family breast cancer history and mammography. Am J Epidemiol, 154, 916-23.

Naghibi SA, Shojaizadeh D, Montazeri A, et al (2014). Evaluating the performance rate of breast cancer screening methods and its relationship with breast cancer risk factors in Mazandaran province. J Mazandaran Univ Med Sci, 23, 118-23.

Qi V, Phillip SP, Hopman WM (2006). Determinants of a healthy lifestyle and use of preventive screening in Canada. $B M C$ Pulic Health, 6, 275-80.

Rakowski W, Meissner H, Vernon SW, et al (2006). Correlates of repetition and recent mammography for women ages 45 to 75 in the 2002 to 2003 health. Information National Trends Survey (HINTS 2003). Cancer Epidemiol Biomarkers Prev, 15, 2093-101.

Salimi Pormehr S, Kariman N, Sheykhan Z, et al (2010). Investigation of breast cancer screening tests performance and affecting factors in women referred to Ardebil's health and medical centers, 2009. J Ardabil Univ Med Sci, 10, 310-8.

Silk KJ, Bigbsy E, Volkman J, et al (2006). Formative research on adolescent and adult perceptions of risk factors for breast cancer. Soc Sci Med, 63, 3124-36.

Strong C, Liang W (2009). Relationships between decisional balance and stage of adopting mammography and Pap testing among Chinese American women. Cancer Epidemiol, 33, 374-80.

Taylor VM, Taplin SH, Urban N, et al (1995). Repetition mammography use among women ages 50-75. Cancer Epidemiol Biomarkers Prev, 4, 409-13.

Taymoori P, Berry T, Farhadifar F (2012). Predicting mammography stage of adoption among Iranian women. $J$ Edu Health Promot, 13, 969-74.

Taymoori P, Berry T, Roshan D (2013). Differences in health beliefs across stage of adoption of mammography in Iranian women. Cancer Nurs, 35, 250-5.

Taymoori P, Molina Y, Roshani D (2015). Effects of a randomized controlled trial to increase repeat mammography screening in Iranian women. Cancer Nurs, 38, 288-96.

Thomas E, Escandón S, Lamyian M, et al (2011). Exploring Iranian women's perceptions regarding control and prevention of breast cancer. Qual Rep, 16, 1214-29.

Thomas EC (2004). African American women's breast memories, cancer beliefs and screening behaviors. Cancer Nurs, 27, 295-302.

Tilburt JC, James KM, Sinicrope PS, et al (2011). Factors influencing cancer risk perception in high risk populations: a systematic review. Hereditary Cancer Clin Pract, 9, 2.

Tolma EL, Stoner JA, Li J, et al (2011). Predictors of regular mammography use among American Indian women in Oklahoma: a systematic review. Hereditary Cancer Clin Pract, 9, 2.

Vernon SW, McQueen A, Tiro JA, et al (2010). Interventions to promote repetition breast cancer screening with mammography: a systematic review and meta-analysis. $J$ Natl Cancer Inst, 102, 1023-39.

Zikmund-Fisher BJ, Fagerlin A, Ubel PA (2010). Risky feelings: why a $6 \%$ risk of cancer does not always feel like $6 \%$. Patient Educ Couns, 81, 87-93. 